\title{
Article
}

\section{Current Videofluoroscopy practice in the United Kingdom: A survey of imaging professionals}

Boaden, Elizabeth, Nightingale, Julie, Hives, Lucy, Bradbury, Carl, Benfield, J, Patel, Tahera and Georgiou, Rachel

Available at http://clok.uclan.ac.uk/35827/

Boaden, Elizabeth ORCID: 0000-0002-4647-6392, Nightingale, Julie, Hives, Lucy ORCID: 0000-0003-4125-4034, Bradbury, Carl, Benfield, J, Patel, Tahera and Georgiou, Rachel (2020) Current Videofluoroscopy practice in the United Kingdom: A survey of imaging professionals. Radiography . ISSN 1078-8174

It is advisable to refer to the publisher's version if you intend to cite from the work. http://dx.doi.org/10.1016/j.radi.2020.11.004

For more information about UCLan's research in this area go to http://www.uclan.ac.uk/researchgroups/ and search for <name of research Group>.

For information about Research generally at UCLan please go to http://www.uclan.ac.uk/research/

All outputs in CLoK are protected by Intellectual Property Rights law, including Copyright law. Copyright, IPR and Moral Rights for the works on this site are retained by the individual authors and/or other copyright owners. Terms and conditions for use of this material are defined in the policies page.

\section{CLoK}

Central Lancashire online Knowledge www.clok.uclan.ac.uk

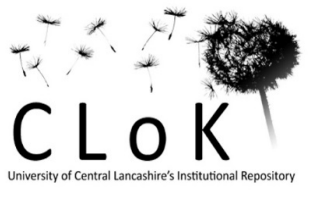




\title{
Current Videofluoroscopy practice in the United Kingdom: A survey of imaging professionals
}

Boaden E, Nightingale J, Hives L, Bradbury C, Benfield J, Patel T, Georgiou R; Radiography 2020

\begin{abstract}
Introduction: Videofluoroscopy (VFSS) is a frequently used radiological investigation for dysphagia and is conducted within a radiology setting by speech and language therapists (SLTs) working alongside imaging personnel (radiologists and/or radiographers). Previous surveys of SLT practice have reported variability in VFSS protocols and procedures. The aim of this study was to explore current clinical practice for VFSS from the perspective of imaging personnel engaged in VFSS within the United Kingdom.

Methods: A comprehensive online survey enabled exploration of current practices of imaging professionals. Target participants were diagnostic imaging personnel (radiographers and radiologists) with experience of working in VFSS clinics. Descriptive statistics describe and summarise the data alongside inferential statistics where appropriate.
\end{abstract}

Results: 54 survey participants represented 40 unique acute healthcare organisations in the UK, in addition to two respondents from the Republic of Ireland. The survey demonstrated high variance in clinical practice across all stages of the VFSS procedure. Clinicians were not always compliant with current UK guidelines and the roles and responsibilities of different professionals working within the clinics were often not clearly defined.

\section{Conclusion:}

Further research is required to develop new international, interprofessional VFSS guidelines to standardise service delivery for VFSS, improving diagnostic accuracy, efficiency and patient experience.

Implications for practice:

In the absence of VFSS guidelines for imaging personnel, practitioners should familiarise themselves with the UK Royal College of Speech and Language Therapists VFSS Position paper; IR(ME)R guidelines and DRLs for the client groups with which they work to guide clinics and improve practice. Clinicians should revisit protocols and clinical governance regarding safe practice in order to improve the quality of care within the VFSS clinic. 


\section{Introduction}

Dysphagia is a health consequence of many congenital and acquired conditions. Videofluoroscopy swallowing studies (VFSS) identify structural and physiological causes of dysphagia to inform patient management, and are conducted by speech and language therapists (SLTs) working alongside imaging professionals.

Previous surveys of SLT practice ${ }^{1-3}$ have reported variability in VFSS protocols and procedures; Benfield et al $^{2}$ also noted a lack of compliance with UK SLT guidelines ${ }^{4}$. No VFSS guideline for imaging personnel exists in the UK. ${ }^{5}$ Only one other published guideline worldwide has a radiologist focus ${ }^{6}$ and none have been published with a radiographer focus. ${ }^{5}$ A systematic review of VFSS guidelines identified a lack of multi-disciplinary input and poor underpinning evidence for many recommendations. ${ }^{5}$ Many are outdated and fail to reflect evolving clinical practices. The lack of a robust UK guideline promotes protocols determined by clinical preferences and equipment availability, rather than evidence based practice. Therefore, it is important to identify current clinical practice to more clearly understand the capability and capacity of VFSS imaging personnel, equipment, technology and service provision and any unwarranted variations in care. This study aims to explore VFSS clinical practice from the perspective of imaging personnel within the United Kingdom.

\section{Methods}

An online survey enabled exploration of current practices of diagnostic imaging professionals with experience of working in VFSS clinics in the UK. This study received ethical approval from the University of Central Lancashire Health Ethics Review Panel (HEALTH 0054 Amendment_4May20).

The survey, hosted on JISC online surveys, ${ }^{7}$ was designed by an expert multidisciplinary team and informed by literature and international guidelines. Following assessment for face and content validity, it was beta tested $(n=8)$ by a UK-wide team of expert VFSS practitioners. Modifications included reducing survey repetition and length, and moderating the balance between multiple choice and supplementary open text boxes. Sixty-two 
questions focussed on eight sections: demographics $(n=5)$; experience $(n=8)$; referral criteria $(n=4)$; governance $(n=9)$; radiation protection $(n=4)$; VFSS practice $(n=23)$; analysis and reporting ( $n=8)$ and further comments $(n=1)$.

Participants were recruited through professional body and special interest group publications, distribution lists and through social media advertising. Initial recruitment was $27^{\text {th }}$ April $-31^{\text {st }}$ May 2020, extended for a further month owing to service pressures during COVID-19. Descriptive statistics describe and summarise data alongside inferential statistics where appropriate. Where varied responses were received, range and mode are reported; for missing responses, percentages are reported of the number of respondents for each question.

\section{Results}

\section{Participant demographics}

Three respondents were excluded because they were not imaging personnel. The remaining 54 participants were geographically diverse, representing 40 unique organisations in the UK, in addition to two respondents from the Republic of Ireland. Eight hospitals were recorded by more than one respondent but, due to variance in VFSS practice within hospitals, these responses were all included separately in the analysis. The method of recruitment to the study negated the calculation of an accurate response rate, however the survey responses represent approximately $30 \%$ of the acute Trusts in England. ${ }^{8}$

Most respondents were radiographers ( $n=52,96.3 \%)$, including 16 Advanced Practitioners and 2 Consultant Practitioners. Their Agenda for Change banding (UK) ranged from 5-8b, with the majority Band 6 or $7(n=42,80.8 \%)$. Additionally, there were two radiologists.

\section{VFSS Workforce}

Most commonly the VFSS service is practitioner-led with radiologists either not present, or available for advice $(n=35,64.8 \%)$. Radiologists are present in some centres only for specific indications (e.g. paediatrics) $(n=5,9.3 \%)$. Caseloads included adult patients only $(n=37$, $69.8 \%)$, paediatric patients only $(n=9,17.0 \%)$ and mixed caseloads $(n=7,13.2 \%)$; minimal 
variation was noted between respondents working with adults and paediatrics. In most departments ( $n=32,59.3 \%$ ) only Specialist Fluoroscopy or Gastrointestinal Imaging Radiographers acquire images, however in some centres rotational radiographers operate the equipment $(n=8,14.8 \%)$.

\section{Training and Experience}

Most respondents had at least two years of VFSS experience $(n=42,77.8 \%)$ and were involved in up to two VFSS clinics per week $(n=52,96.3 \%)$. Three-quarters ( $n=39,73.6 \%)$ had received VFSS-specific training, with in-house training the most frequently reported $(n=35$, $68.6 \%)$. Formalised training included postgraduate modules $(n=17,33.3 \%)$, CPD study days ( $n=14,27.5 \%)$, e-learning ( $n=11,21.6 \%)$, and formal lectures $(n=5,9.8 \%)$. Table 1 demonstrates associations between postgraduate study and various VFSS practice parameters.

\begin{tabular}{|c|c|c|c|c|}
\hline Association & $\begin{array}{l}\text { Statistical } \\
\text { tests }\end{array}$ & Result & Interpretation & Conclusion \\
\hline $\begin{array}{l}\text { PG study (PG study/ no PG } \\
\text { study) and usual pulse } \\
\text { rate selection (<15pps/ } \\
\geq 15 p p s)\end{array}$ & $\begin{array}{l}X^{2}(1)=0.400 \\
p=0.842\end{array}$ & $\begin{array}{l}\text { No statistically } \\
\text { significant } \\
\text { association. }\end{array}$ & $\begin{array}{l}\text { Those who had } \\
\text { completed postgraduate } \\
\text { study were not more } \\
\text { likely to select an } \\
\text { appropriate pulse rate. }\end{array}$ & $\begin{array}{l}\text { Knowledge } \\
\text { gap in PG } \\
\text { learning; } \\
\text { need for CPD }\end{array}$ \\
\hline $\begin{array}{l}\text { PG study (PG study/ no PG } \\
\text { study) and radiographer's } \\
\text { contribution to the } \\
\text { definitive VFSS report } \\
\text { (contribution/ no } \\
\text { contribution). }\end{array}$ & $\begin{array}{l}X^{2}(1)=7.299 \\
p=0.007 \\
\varnothing=0.368 \\
p=0.007\end{array}$ & $\begin{array}{l}\text { A statistically } \\
\text { significant } \\
\text { association; strength } \\
\text { of the association } \\
\text { between the two } \\
\text { variables was } \\
\text { medium. } \\
\end{array}$ & $\begin{array}{l}\text { Those who had } \\
\text { completed postgraduate } \\
\text { study were significantly } \\
\text { more likely to contribute } \\
\text { to the definitive VFSS } \\
\text { report. }\end{array}$ & $\begin{array}{l}\text { Relevant PG } \\
\text { education } \\
\text { facilitates } \\
\text { greater } \\
\text { multi- } \\
\text { disciplinary } \\
\text { working } \\
\end{array}$ \\
\hline $\begin{array}{l}\text { PG study (PG study/ no PG } \\
\text { study) and imaging of the } \\
\text { oesophagus (routinely/ } \\
\text { when indicated/ no } \\
\text { imaging). }\end{array}$ & $\begin{array}{l}X^{2}(2)=5.271 \\
p=0.072 \\
V=0.268 \\
p=0.149\end{array}$ & $\begin{array}{l}\text { No statistically } \\
\text { significant } \\
\text { associations } \\
\text { (approaching } \\
\text { significance). } \\
\text { Cramer's } V \text { test of } \\
\text { effect size revealed a } \\
\text { weak association, but } \\
\text { this was not } \\
\text { significant. }\end{array}$ & $\begin{array}{l}\text { Those who had } \\
\text { completed postgraduate } \\
\text { study were not more } \\
\text { likely to offer } \\
\text { oesophageal screening. }\end{array}$ & $\begin{array}{l}\text { Relevant PG } \\
\text { education } \\
\text { does not } \\
\text { result in } \\
\text { more service } \\
\text { flexibility }\end{array}$ \\
\hline
\end{tabular}

Table 1: Associations between postgraduate study completion and VFSS practice parameters. Key PG - postgraduate; pps - pulses per second; CPD - continuing professional development 
Over half of respondent's competency to practice VFSS had not been formally assessed $(n=33,61.1 \%)$. Only $5(9.4 \%)$ rated themselves as very knowledgeable and yet $29(53.7 \%)$ rated themselves as very confident in undertaking the procedure. Generally, self-rated confidence and knowledge of VFSS increased with experience, as shown in Figure 1.

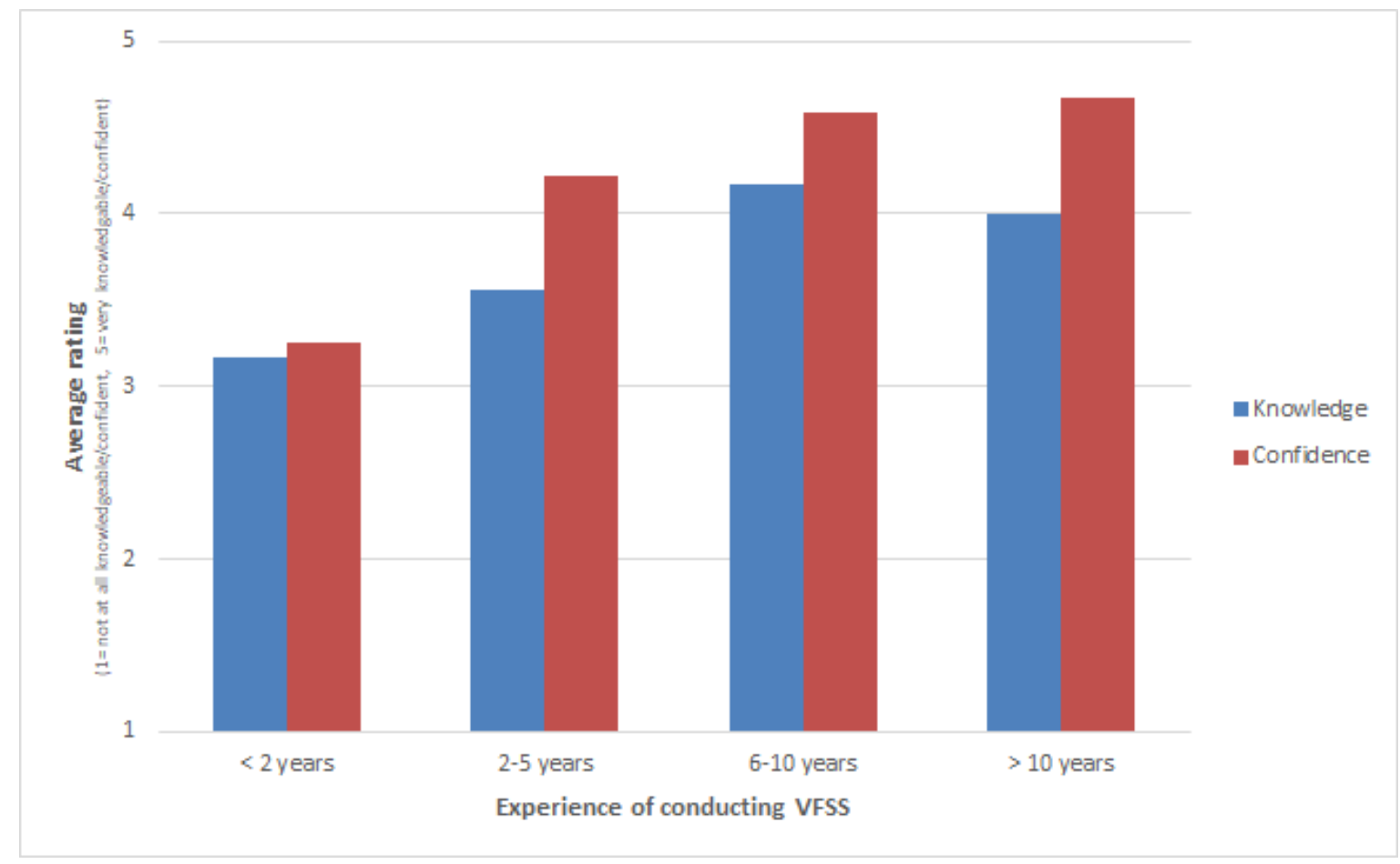

Figure 1. Self-reported confidence and knowledge of VFSS reported by radiographers and radiologists

\section{Referral criteria}

Radiologists and/or a named radiographer justified VFSS referrals $(n=42,77.8 \%)$ in most departments. A clinical bedside swallowing assessment is a pre-requisite for VFSS ( $n=33$, 61.1\%), however, 17 (31.5\%) were unsure of this requirement. Patient information was available for out-patients in most centres $(n=42,77.8 \%)$, though less frequently for inpatients ( $n=29,53.7 \%)$.

\section{Governance and Safety}

The majority ( $n=40,74.1 \%$ ) reported having a VFSS protocol (Table 2$)$. Ten respondents (19.6\%) reported seeking written consent from patients, though verbal consent was more common, subsequently recorded on Radiology Information Systems ( $n=23,45.1 \%)$ or in- 
patient notes $(n=14,27.5 \%)$. Consent without documentation was reported in $7(13.7 \%)$ responses, whilst 5 (9.8\%) did not know if consent was recorded.

\begin{tabular}{|l|c|c|}
\hline Guidance & N & \% \\
\hline Key components of the procedure (e.g. contrast) & 40 & 100.0 \\
\hline Action in response to aspiration & 37 & 94.9 \\
\hline Action in response to allergic reaction & 31 & 77.5 \\
\hline Action in response to incidental findings & 30 & 75.0 \\
\hline Personal Protective Equipment (PPE) & 28 & 70.0 \\
\hline Advice on Frame rates & 25 & 62.5 \\
\hline Advice on Pulse rates & 23 & 57.5 \\
\hline All above elements & $\mathbf{1 6}$ & $\mathbf{4 0 . 0}$ \\
\hline
\end{tabular}

Table 2: Contents of existing protocols and Standard Operating Procedures for VFSS

Food allergies were checked by 23 (44.2\%) with 33 (63.5\%) respondents checking contrast allergies. Patient group directions were available for VFSS contrast preparations including barium sulphate powders ( $n=31,57.4 \%)$, Gastromiro $(n=10,19.6 \%)$, Omnipaque $(n=29$, $54.7 \%$ ) and Baritop ( $n=23,43.4 \%)$. Barium Sulphate preparations were used in 19 (35.2\%) clinics, water soluble contrasts in $15(27.8 \%)$ clinics and 18 (33.3\%) used both. Few respondents using barium preparations $(10 / 37,25.7 \%)$ were able to identify the concentrations used, stating widely varying weight to volume ratios (25\%-98\%). The remainder did not know or said it was the responsibility of the SLTS.

The International Dysphagia Diet Standardisation Initiative (IDDSI) framework ${ }^{9}$ supports the implementation of a common language relating to fluid and food textures which aims to improve communication between health professionals and care givers. Seventeen respondents (31.5\%) reported having all IDDSI framework ${ }^{9}$ diet and fluids available for assessment, if required, with 16 (29.6\%) having some textures available. The majority of respondents ( $n=43,79.6 \%)$, however, reported that SLTs decided what textures should be trialled during VFSS sessions.

\section{Staff Radiation Protection}

Respondents reported always/often wearing lead-equivalent PPE consisting of: thyroid shields ( $n=48,88.9 \%)$, full length aprons ( $n=47,88.7 \%)$, half aprons with skirt component 
$(n=36,75.0 \%)$, gloves $(n=16,32.7 \%)$, and glasses $(n=1,2.1 \%)$. Some reported that protective glasses ( $n=12,25.5 \%)$ and gloves $(n=7,14.3 \%)$ were not required.

The most prevalent Personal Protective actions reported were using a radiation monitoring badge $(n=51,98.1 \%)$, decreasing time $(n=38,74.5 \%)$ or increasing distance $(n=36,70.6 \%)$ from fluoroscopy equipment, and standing behind a static $(n=28,56.0 \%)$ or portable $(n=15$, 28.8\%) lead glass screen. Eight (16.0\%) respondents reported using other dosimetry (e.g. eye, finger) and 2 (4.0\%) standing behind another member of staff.

Radiation monitoring badges were routinely worn by imaging personnel ( $n=45 ; 83 \%)$. Some respondents issued badges to individual SLTs $(n=20,37 \%)$, whilst $14(26 \%)$ allocated badges to the SLT department as a shared resource. Badges were worn under the apron $(n=39$, $75.0 \%)$ at pelvic level $(n=36,69 \%)$ or at thyroid level $(n=10,19.2 \%)$. Six respondents wore two badges (pelvic and thyroid level; $n=6,11.5 \%$ ); thirteen $(25.0 \%)$ reported wearing a badge outside their apron.

\section{VFSS Acquisition}

Specialist VFSS clinics are displayed in Table 3, with the range of imaging techniques used displayed in Table 4.

\begin{tabular}{|l|c|c|c|c|}
\hline Type of clinic & $\begin{array}{l}\text { Number (\%) of } \\
\text { hospitals* running } \\
\text { each type of clinic }\end{array}$ & $\begin{array}{l}\text { Range (mode) of } \\
\text { number of patients } \\
\text { per session }\end{array}$ & $\begin{array}{l}\text { Range (mode) of } \\
\text { number of patients } \\
\text { seen per month }\end{array}$ & $\begin{array}{l}\text { Range (mode) of } \\
\text { time, in minutes, } \\
\text { allocated per patient }\end{array}$ \\
\hline $\begin{array}{l}\text { Head and } \\
\text { neck }\end{array}$ & $9(22.5)$ & $2-5(2$ and 3) & $3-24(4$ and 12) & $15-30(30)$ \\
\hline $\begin{array}{l}\text { Ear nose and } \\
\text { throat }\end{array}$ & $6(15.0)$ & $2-5(3$ and 4) & $4-16(4$ and 12) & $20-30(30)$ \\
\hline Paediatric & $10(25.0)$ & $1-7(3)$ & $3-63(4)$ & $20-80(30)$ \\
\hline $\begin{array}{l}\text { General VFSS } \\
\text { referral clinics }\end{array}$ & $23(57.5)$ & $1-12(2)$ & $2-144(8)$ & $15-45(30)$ \\
\hline
\end{tabular}

Table 3: Types of clinics running at the different Trusts

*Hospitals counted only once. 


\begin{tabular}{|l|c|c|c|}
\hline Practice elements & Adopted & Not adopted & $\begin{array}{c}\text { Unsure/not } \\
\text { routinely adopted }\end{array}$ \\
\hline $\begin{array}{l}\text { Magnification for lateral } \\
\text { oro/pharyngeal screening }\end{array}$ & $32(59.3 \%)$ & $20(37.0 \%)$ & $2(3.7 \%)$ \\
\hline $\begin{array}{l}\text { Routinely use filters for lateral } \\
\text { oro/pharyngeal screening }\end{array}$ & $28(51.9 \%)$ & $18(33.3 \%)$ & $8(14.8 \%)$ \\
\hline $\begin{array}{l}\text { Use of a specialist fluoroscopy } \\
\text { chair }\end{array}$ & $26(26.0 \%)$ & $22(42.3 \%)$ & $4(7.7 \%)$ \\
\hline Carry out manofluoroscopy & $2(4.1 \%)$ & $43(87.8 \%)$ & $4(8.2 \%)$ \\
\hline $\begin{array}{l}\text { Capture radiographic (spot) } \\
\text { images }\end{array}$ & $15(28.8 \%)$ & $22(42.3 \%)$ & $15(28.8 \%)$ \\
\hline $\begin{array}{l}\text { Capture images from the } \\
\text { display monitor (fluorograb) }\end{array}$ & $37(69.8 \%)$ & $6(11.3 \%)$ & $10(18.9 \%)$ \\
\hline $\begin{array}{l}\text { Storage of sound data } \\
\text { Annotation of VFSS images } \\
\text { during the procedure }\end{array}$ & $12(23.5 \%)$ & $37(72.5 \%)$ & $2(3.9 \%)$ \\
\hline
\end{tabular}

Table 4: Imaging techniques within the VFSS procedure

Images are saved on screening loops $(n=45,83.8 \%)$, with the patient positioned predominantly in the lateral position $(n=50,92.6 \%) ; 21(38.9 \%)$ rarely or never image in the AP/PA position. Five respondents (9.4\%) routinely imaged the oesophagus, 29 (54.7\%) only when indicated, whilst 19 (35.8\%) never examined the oesophagus. The anatomical boundaries for lateral position collimation are displayed in Table 5.

\begin{tabular}{|c|c|}
\hline Anatomical boundary & Radiographic or anatomical landmark \\
\hline Superior & $\begin{array}{l}\text { - Palate or roof of mouth ( } n=12,30.0 \%) \\
\text { - Below orbital margin, nasal septum, above nasopharynx ( } n=19 \text {, } \\
47.5 \%) \\
\text { - A range of less reliable external landmarks but most } \\
\text { acknowledged the need to reduce eye dose }\end{array}$ \\
\hline Inferior & $\begin{array}{l}\text { - Bony landmarks e.g. named vertebrae, suprasternal notch }(n=18 \text {, } \\
45.0 \%) \\
\text { - Soft tissue landmarks e.g. upper oesophagus, tracheal or } \\
\text { laryngeal ( } n=10,25.0 \%) \\
\text { - Less reliable landmarks e.g. shoulders }(n=9,22.5 \%)\end{array}$ \\
\hline Anterior & $\begin{array}{l}\text { - External landmarks e.g. lips, skin border ( } n=30,75.0 \%) \\
\text { - } \quad \text { Range of further responses e.g. incisors, mid-mouth or neck }\end{array}$ \\
\hline Posterior & $\begin{array}{l}\text { - Bony and soft tissue landmarks indicating inclusion of the } \\
\text { posterior C spine ( } n=27(69.2 \%) \\
\text { - Some include none or only part of the spine }(n=6,15.4 \%) \\
\text { - Less precise landmarks e.g. occiput, behind the oesophagus }\end{array}$ \\
\hline
\end{tabular}

Table 5: The boundaries of collimation for lateral oro/pharyngeal fluoroscopy 
Frame rates and pulse rates (Table 6) were highly variable; many frame rate selections showed a lack of understanding, ranging from 2-30 frames per second (fps), with the most frequently used frame rate of $15 \mathrm{fps}$ ( $n=25,48.1 \%)$. Average fluoroscopy time was highly variable (<1->5 mins; mode 3-5 mins, $n=27,50.9 \%)$. Thirty-nine $(72.2 \%)$ routinely set a fluoroscopy timer to alert the operator that a pre-set screening time (3-5 minutes) was reached; thirteen $(24.1 \%)$ did not use a timer. The majority $(n=53,98.1 \%)$ recording screening time and radiation doses, yet over half $(n=26,52.0 \%)$ were unfamiliar with VFSS Diagnostic Reference Levels (DRLs). Given a selection of DRL values, only 18 (36.0\%) accurately identified the adult DRL as $3.4 \mathrm{Gycm}^{2}$, whilst most were unaware of paediatric DRLS.

\begin{tabular}{|l|c|c|}
\hline Pulses per second (pps) & N & \% \\
\hline Under 15pps (range 2-10pps) & 15 & 28.3 \\
\hline 15pps & 14 & 26.4 \\
\hline 30pps & 14 & 26.4 \\
\hline $\begin{array}{l}\text { Continuous fluoroscopy (approx. } \\
\text { 30pps) }\end{array}$ & 6 & 11.3 \\
\hline Unsure & 4 & 7.5 \\
\hline
\end{tabular}

Table 6: Pulses per second used in VFSS service

\section{Fluoroscopy Equipment, Analysis and Reporting}

Fluoroscopy equipment included C-arm fluoroscopy systems ( $n=34,61.1 \%)$, overcouch/remote operating systems $(n=14,25.9 \%)$ and under-couch $x$-ray tube systems $(n=5$, 9.3\%). Digital flat plate detectors $(n=9,16.7 \%)$ and traditional image intensifier systems ( $n=8,14.8 \%$ ) were also acknowledged, with equipment predominantly supplied by Siemens ( $n=33,68.8 \%)$ and Philips ( $n=14,29.2 \%)$. Image storage was mainly on PACS ( $n=44,83.0 \%)$ although other methods included external media ( $n=12,22.6 \%)$.

Fluoroscopy systems ranged from $<5$ to $>10$ years $(n=19,35.8 \%)$. Unsuitable equipment including poor quality DVD systems and display monitors, the inability to save screening loops or to select higher pulse rates, resulted in inadequate image quality ( $n=14,46.7 \%)$. A third ( $n=10,33.3 \%)$ of respondents, however, indicated good quality images with newer equipment. 
All the respondents (100\%) reported that their patients receive/sometimes receive a verbal report by SLTs immediately following the procedure $(n=41,77.3 \%)$. This mainly occurs in the fluoroscopy room $(n=42,79.2 \%)$, and include/sometimes include $(n=46,93.9 \%)$ patient review of images. Thirteen (24.5\%) respondents also provided VFSS-specific aftercare information sheets. VFSS reporting in most centres is undertaken solely by SLTs with no imaging personnel contribution ( $n=30,56.6 \%)$. Radiographers in some centres contribute to the initial analysis upon request $(n=13,24.5 \%)$ and may write specific aspects of the report (Table 7). Many clinics ( $n=21,39.2 \%$ ) generate two separate reports, stored on the SLT and radiology systems respectively, or store reports exclusively on SLT ( $n=15,29.4 \%)$, or radiology systems $(n=12,23.5 \%)$.

\begin{tabular}{|l|l|c|}
\hline Category & Contribution & $\mathbf{( \% )}$ \\
\hline Author of definitive report & SLT only & $30(56.6 \%)$ \\
\cline { 2 - 3 } & radiologist only & $6(11.3 \%)$ \\
\cline { 2 - 3 } & radiographer only & $1(1.9 \%)$ \\
\cline { 2 - 3 } & radiologist and SLT & $5(9.4 \%)$ \\
\cline { 2 - 3 } & $\begin{array}{l}\text { Advanced Radiographer Practitioner and } \\
\text { SLT }\end{array}$ & $5(9.4 \%)$ \\
\hline Radiographer contribution to \\
analysis and reporting & anatomical or structural problems & $22(41.5 \%)$ \\
\cline { 2 - 3 } & oesophageal analysis & $16(30.2 \%)$ \\
\cline { 2 - 3 } & $\begin{array}{l}\text { joint assessment of penetration and } \\
\text { aspiration rating scales }\end{array}$ & $10(18.9 \%)$ \\
\cline { 2 - 3 } & joint assessment of residue rating scales & $8(15.1 \%)$ \\
\hline
\end{tabular}

Table 7: Contribution to VFSS analysis and report

\section{Discussion}

A lack of standardisation across all stages of the VFSS procedure was identified; as in the survey by Benfield et al ${ }^{2}$, clinical practice in many centres varied significantly from UK SLT guidance 4 . One respondent reported that 'having worked in different Trusts, the differences in practices is quite noticeable.' However, the variation is not only between, but also within the same organisation.

The survey demonstrates a need for standardised and accredited VFSS education. Knowledge was poor in some fundamental aspects of VFSS practice, exemplified by many 'don't know' answers related to protocols, pre-requisites for VFSS, DRLs, and contrast agent 
volumes and densities. Many deferred contrast preparation decisions to the SLT, however a recent survey of UK SLTs also demonstrated an alarming lack of knowledge in this area of practice $^{2}$. While few respondents rated their VFSS knowledge as high/very high, more than half ( $n=29,53.7 \%$ ) self-rated as very confident in VFSS. Recognising that confidence does not necessarily equate to initial competence or ongoing capability ${ }^{10}$, it is concerning that over half of respondents' competency to practice VFSS had not been formally assessed.

Videofluoroscopy is mostly practitioner-led (64\% responses) with the radiologists not routinely present; current SLT guidance relating to radiologist-led services is clearly outdated. ${ }^{4}$ This move towards practitioner-led services has been shown to be safe, efficient and cost-effective, ${ }^{2,11,12}$ when supported by an agreed protocol for practice. Such protocols need to have flexibility to meet individual patient needs, yet this survey highlighted examples of restricted practice in terms of the scope of the imaging provided. For example, the majority $(n=50,92.6 \%)$ imaged the patient predominantly in the lateral position which is an appropriate strategy to assess transient aspiration and penetration. ${ }^{13}$ However 21 (38.9\%) rarely or never image the patient in the AP/PA (antero-posterior / postero-anterior) position; this is surprising as this position may provide valuable information related to the laterality of any deficit (such as may occur following a stroke). ${ }^{13}$ Additionally, while the VFSS is primarily an examination of the oro-pharynx, a brief review of the oesophageal swallowing phase is occasionally, if not always, indicated. ${ }^{14}$ Fine mucosal detail will not be visualised but this 'oesophageal sweep' reviews unhindered flow through the oesophagus and into the stomach; in this study 19 (35.8\%) imaging personnel never examined the oesophagus.

In this survey, poorly-defined responsibilities were highlighted where radiographers deferred to SLTS for decisions on consent, allergies, consistencies offered, analysis and reporting. Reports in many centres were issued by the SLT without radiographer involvement, an opportunity lost to draw on the unique skills of both professions. Radiation protection, however, was clearly within the domain of the radiographer, ensuring safety and care of the patient, their carers and other staff within the fluoroscopy room. An international survey of SLTs also acknowledged the radiographer as the most influential figure in ensuring visiting SLTs complied with best practice ${ }^{1}$. Most radiation protection 
procedures were consistently reported, however the issuing of personnel dosimetry badges to SLTs was highly variable, with one quarter of badges allocated to the SLT department as a shared resource. This is a controversial issue as dosimetry may demonstrate SLT dose levels lower than thresholds required for monitoring ${ }^{15}$, yet sharing radiation badges precludes investigation of any significant detected doses; balancing the cost of monitoring against any reassurance that it may provide is challenging ${ }^{1}$.

Radiation monitoring badges were routinely worn by imaging personnel $(n=45 ; 83 \%)$; it is likely that those who did not wear a dosimetry badge were working within fluoroscopy rooms equipped with remote-controlled operating systems ( $n=14,25.9 \%)$. These enable the radiographer to control the equipment from an operator console in a shielded booth, protecting the radiographer from secondary radiation exposure. One quarter of respondents reported wearing a single dosimetry badge outside their lead equivalent apron at thyroid level which is completely inconsistent with any UK published guidance. ${ }^{16}$ However, $58 \%$ of SLTs in a recent international study also followed this practice, rising to $97 \%$ of USA participants $(n=111)^{1}$; this is consistent with guidance from the USA. ${ }^{17}$ These inconsistencies in international guidelines have previously been highlighted by Boaden et $\mathrm{al}^{5}$ and are a significant barrier to the dissemination of evidence based practice.

Patient radiation doses associated with adult videofluoroscopy can be maintained at a low level by using an optimised imaging protocol; UK national diagnostic reference levels are currently set at $3.4 \mathrm{Gycm}^{2}$ and a screening time of 3.5 minutes. ${ }^{18}$ Dose and image quality optimisation is an interesting trade-off in videofluoroscopy, with higher pulse rates yielding optimal image quality but at the expense of higher dose. While clinical justification for any VFSS imaging request must be present and must comply with the As Low as Reasonably Practicable (ALARP) principle ${ }^{16}$, the additional risk of harm from higher pulse rates will be outweighed by the improvements in image quality with a consequent higher diagnostic yield of significant pathology such as aspiration. In this study, knowledge of VFSS imaging parameters such as pulse and frame rates was highly variable. Reflecting previous studies ${ }^{1,2,3}$, some extreme outliers and 'don't know' responses suggest a lack of understanding, even amongst radiographers with postgraduate qualifications, despite definitions of these parameters being offered within the survey. While most participants use 
15 or more pulses per second (pps), $28.3 \%$ use $<15 p p s$. These low pulse rates have the potential to miss transient penetration and aspiration which may occur momentarily within the rapid transit of contrast agent through the oro-pharynx. ${ }^{19-22}$ This may lead to inappropriate therapeutic recommendations and subsequent patient harm. Data from empirical studies ${ }^{19-22}$ investigating pulse rate selection in a small sample of paediatric and stroke patients offer equivocal recommendations of either $15 \mathrm{pps}$ or $30 \mathrm{pps}$. While 30pps may be optimal for image quality, data storage capacity at the highest pulse rates is a limiting factor in some centres.

The survey highlights potential risks including inconsistencies in checking and reporting allergies (detailed within current RCSLT guidelines) ${ }^{4}$ and storing images and reports in different repositories. A single repository for VFSS that is accessible by all professionals is strongly recommended to increase safety in patient care. Ageing equipment is also a risk; many respondents report fluoroscopy imaging systems over a decade old. These less flexible systems use analogue rather than digital capabilities, potentially generating poor quality images with a higher radiation dose. Respondents reported frustration regarding their ageing equipment, noting that $\mathrm{CT} / \mathrm{MR}$ equipment replacement programmes take precedence; recent procurement initiatives in England, while welcomed, again prioritise cross-sectional imaging. ${ }^{23}$

The UK survey achieved wide geographical reach, however a limitation of web-based surveys is the lack of control over participant selection, introducing potential respondent bias into the study. Paediatric service respondents were not reported separately, however very few differences were identified, including lower diagnostic reference levels and developmentally appropriate foods and drinks given during the procedure. This supports the development of clinical practice guidelines that include paediatric practice, with these caveats identified.

In order to reduce unsafe variation in VFSS practice, further robust research is required in all domains of VFSS to inform an evidence-based clinical practice guideline, including the optimisation of image acquisition and display parameters to ensure doses are commensurate with the ALARP principle whilst offering diagnostic accuracy ${ }^{16}$. Respondents 
agreed that formalised guidance is required, with one respondent stating they are 'very keen to move forward together'. This suggests that an inter-professional clinical practice guideline would be well-received.

\section{Conclusion}

This survey of UK imaging professional clinical practice demonstrates a great variation across all videofluoroscopy practice domains. Previous research reports the wide variation in global clinical guidelines which inadvertently generates this localised variation in practice. Further research is required to develop new international, inter-professional VFSS guidelines to standardise service delivery, improving diagnostic accuracy, efficiency and patient experience.

\section{References}

1. Parsotam H, Warren-Forward H, Shields $\mathrm{M}, \mathrm{McNulty} \mathrm{J}$, Shaw Bonilha $\mathrm{H}$ et al. Are radiographers an influencing factor in the radiation practices of speech-language therapists performing videofluoroscopic swallowing studies? Radiography 2020:26(4):e229-e237

https://doi.org/10.1016/j.radi.2020.03.003.

2. Benfield JK, Michou E, Everton LF, Mills C, Hamdy S, Bath PM et al. The Landscape of Videofluoroscopy in the UK: A Web-Based Survey. Dysphagia 2020. https://doi.org/10.1007/s00455020-10130-1.

3. Power M, Laasch H-U, Kasthuri RS, Nicholson DA, Hamdy S. Videofluoroscopic assessment of dysphagia: a questionnaire survey of protocols, roles and responsibilities of radiology and speech and language therapy personnel. Radiography 2006; 12(1):26-30.

https://doi.org/10.1016/j.radi.2005.03.003

4. Royal College of Speech and Language Therapists. Videofluoroscopic evaluation of oropharyngeal swallowing function (VFS): The role of the speech and language therapists. RCSLT Position Paper 2013. London: Royal College of Speech and Language Therapists. https://www.rcsit.org//media/Project/RCSLT/videofluoroscopic-position-paper.pdf

5. Boaden E, Nightingale J, Bradbury C, Hives L, Georgiou R. Clinical practice guidelines for videofluoroscopic swallowing studies: A systematic review. Radiography 2020; 26(2):154-162. https://doi.org/10.1016/j.radi.2019.10.011.

6. American College of Radiology. ACR-SPR. Practice parameter for the performance of the modified barium swallow. 2017. Available at https://www.acr.org//media/ACR/Files/Practice-Parameters/Modified-Ba-Swallow.pdf Accessed 07.09.20

7. Jisc online surveys. Available at https://www.onlinesurveys.ac.uk/ Accessed07.09.20 
8. NHS Confederation. NHS statistics, facts and figures. Available at:

https://www.nhsconfed.org/resources/key-statistics-on-the-nhs Accessed 07.09.20

9. International Dysphagia Diet Standardisation Initiative (IDDSI). https://iddsi.org/ Accessed 11.09.20

10. Mitchell P, Nightingale J, Reeves P. Competence to capability: An integrated career framework for sonographers. Radiography 2019; 25:378-384

11. Newman RD, Nightingale J. Improving patient access to videofluoroscopy services: role of the practitioner-led clinic. Radiography 2011; 17(4):280-3.

12. Benfield JK, Hardman T, Minford J, England TJ. Royal Derby hospital videofluoroscopy clinic: a service review and quality improvement project. Int J Stroke 2018; 13(3S):10-65.

13. Newman R \& Nightingale J. Videofluoroscopy: A multi-disciplinary team approach. 2012. San Diego: Plural Publishing.

14. Gaziano J, Watts S. (Speech-Language Pathology) Screening for Esophageal Dysphagia: Enhancing the Clinical Utility of the Modified Barium Swallow. Perspectives of the ASHA special interest groups 2018;3(13):67-74. https://doi.org/10.1044/persp3.SIG13.67

15. Speech Pathology Australia. Videofluoroscopic swallow study clinical guideline. Speech Pathology Australia; 2013.

https://www.speechpathologyaustralia.org.au/SPAweb/Members/Clinical Guidelines/spaweb/Mem bers/Clinical Guidelines/Clinical Guidelines.aspx?hkey=f66634e4-825a-4f1a-910d-644553f59140

16. The lonising Radiation (Medical Exposure) Regulations 2017: Guidance. Department of Health and Social Care 2018, no 1322. https://www.gov.uk/government/publications/ionising-radiationmedical-exposure-regulations-2017-guidance

17. NHS Interagency Working Group on Medical Radiation and U.S. Environmental Protection Agency. Radiation Protection Guidance for Diagnostic and Interventional X-ray Procedures. Federal Guidance Report No. 14. November 2014. Washington, D.C. 20460. Available from: https://www.epa.gov/radiation/ federal-guidance-report-no-14-radiation-protection-guidancediagnostic-andinterventional.

18. Health Protection Agency. National Diagnostic Reference Levels (NDRLs) January 2016. https://www.gov.uk/government/publications/diagnostic-radiology-national-diagnostic-referencelevels-ndrls/national-diagnostic-reference-levels-ndrls\#national-drls-for-general-radiography-andfluoroscopy

19. Cohen MD. Can we use pulsed fluoroscopy to decrease the radiation dose during video fluoroscopic feeding studies in children? Clinical Radiology 2009; 64(1):70-73.

20. Bonilha HS, Blair J, Carnes B, Huda W, Humphries K, McGrattan K et al. Preliminary investigation of the effect of pulse rate on judgments of swallowing impairment and treatment recommendations. Dysphagia 2013: 28(4):528-538 https://doi.org/10.1007/s00455-013-9463-z 
21. Mulheren RW, Azola A, González-Fernández M. Do ratings of swallowing function differ by Videofluoroscopic rate? An exploratory analysis in patients after acute stroke. Arch Phys Med Rehabil 2019; 100(6):1085-1090. doi:10.1016/j.apmr.2018.10.015

22. Layly J, Marmouset F, Chassagnon G, Bertrand P, Sirinelli D, Cottier JP et al. Can we reduce frame rate to 15 images per second in Pediatric Videofluoroscopic Swallow Studies? Dysphagia 2020;

35(2):296-300. doi: 10.1007/s00455-019-10027-8.

23. NHS England and NHS Improvement. Transforming imaging services in England: a national strategy for imaging networks November 2019. NHS Improvement publication code: CG 51/19. https://improvement.nhs.uk/documents/6119/Transforming imaging services.pdf 